\title{
Comparative Effects of Metformin and Dipeptidyl Peptidase-4 Inhibitors in Japanese Obese Patients with Type 2 Diabetes: A Claims Database Study
}

\author{
Masato Odawara · Sumiko Aoi · Tomomi Takeshima • \\ Kosuke Iwasaki
}

Received: April 22, 2021 / Accepted: June 15, 2021 / Published online: July 4, 2021

(C) The Author(s) 2021

\section{ABSTRACT}

Introduction: Metformin has demonstrated favorable effects on glycemic control in patients with type 2 diabetes (T2D), regardless of the body mass index (BMI). On the contrary, dipeptidyl peptidase-4 inhibitors (DPP-4is) are reportedly less effective in patients having high BMI values ( $\geq 25$ or $\geq 30$ ). The aim of this study was to compare metformin and DPP-4is as firstline treatment for their effects on glycemic control and improvement of other health outcomes among obese and non-obese Japanese patients with T2D.

Methods: A Japanese health insurance claims database that also included annual medical checkup data was used. This database included data on company employees who were

Supplementary Information The online version contains supplementary material available at https:// doi.org/10.1007/s13300-021-01101-2.

\section{Odawara $(\square)$}

Department of Diabetes, Metabolism and Endocrinology, Tokyo Medical University, 6-7-1

Nishi-Shinjuku, Shinjuku-ku, Tokyo, Japan

e-mail: odawara@tokyo-med.ac.jp

\section{S. Aoi}

Medical Affairs, Sumitomo Dainippon Pharma Co., Ltd., 1-13-1, Kyobashi, Chuo-ku, Tokyo, Japan

T. Takeshima $\cdot$ K. Iwasaki

Milliman Inc., 8F, Urbannet Kojimachi Building,

1-6-2 Kojimachi, Chiyoda-ku, Tokyo, Japan members of health insurance societies and their family members. Most patients were aged $<65$ years and most were men. Inclusion criteria were: (1) a first T2D diagnosis between May 2010 and June 2017; (2) either metformin or a DPP-4i prescribed as the first-line antidiabetic therapy; and (3) glycated hemoglobin (HbA1c) and BMI data available for the 3-month period immediately preceding the initiation of antidiabetic treatment (baseline). The reduction rate in excessive HbA1c ( $>6.5 \%$; primary outcome) and changes in fasting plasma glucose, BMI, triglyceride, cholesterol, and abdominal circumference (secondary outcomes) at 12 months from baseline were compared between treatments.

Results: When evaluated relative to the baseline BMI, the mean reduction rate in excessive HbA1c tended to be higher in the metformin group than in the DPP-4i group, especially in patients with $\mathrm{BMI} \geq 25$. Similarly, significant improvement was observed in most outcomes in obese patients prescribed metformin compared to those prescribed a DPP-4i. In contrast, in patients with $\mathrm{BMI}<25$, HbA1c reduction was greater in patients prescribed DPP-4i and fewer outcomes showed significant improvement in patients prescribed metformin.

Conclusion: In obese Japanese patients with $\mathrm{T} 2 \mathrm{D}$, greater improvements in glycemic control and other outcomes were seen with metformin as first-line treatment for T2D compared with DPP-4is, although some limitations regarding 
the database information should be considered.

Keywords: Body mass index; Database research; Dipeptidyl peptidase-4 inhibitors; Glycemic control; Metformin; Obesity; Type 2 diabetes

\section{Key Summary Points}

Why carry out this study?

Obesity is often associated with the development of type 2 diabetes (T2D), contributing to worsening diabetic symptoms with increasing risk of cardiovascular disease.

Metformin has been reported to have favorable effects on glycemic control in patients with T2D, regardless of their body mass index (BMI); in contrast, dipeptidyl peptidase-4 inhibitors (DPP-4is) are reportedly less effective in obese patients.

This study compared metformin and DPP-4is as first-line treatment for their effects on glycemic control and improvement of other health outcomes among obese and non-obese Japanese patients with T2D.

\section{What was learned from the study?}

Mean reduction rate of excessive glycated hemoglobin ( $\mathrm{HbA1c}>6.5 \%$ ) tended to be higher in the metformin group than in the DPP-4i group, especially if the BMI $\geq$ 25 , and significant improvement was observed in most outcomes in obese patients $(\mathrm{BMI} \geq 25)$ who were prescribed metformin compared to those who were prescribed DPP-4i.

The results suggest that the effect on glycemic control and improvement in other health outcomes was higher with metformin treatment as a first-line drug compared with DPP-4is in Japanese obese patients with T2D.

\section{DIGITAL FEATURES}

This article is published with digital features, including a summary slide, to facilitate understanding of the article. To view digital features for this article go to https://doi.org/10.6084/ m9.figshare.14785734.

\section{INTRODUCTION}

Obesity is often associated with the development of type 2 diabetes (T2D) and contributes to worsening diabetic symptoms and increasing risk of cardiovascular disease. In 2016, the number of patients with and prevalence of T2D in Japan was estimated to be around 10 million and $12.1 \%$, respectively [1]. T2D has become a major health issue in Japan, with the number of patients with both obesity and T2D increasing. In addition, the mean body mass index (BMI) has been increasing to around 25 and maintained over years in patients with T2D [2]. To achieve the treatment goals for T2D-prevention of complications and maintenance of quality of life and life expectancy equivalent to that of healthy people $[3,4]$-appropriate treatment that considers the conditions of each patient, including BMI, is crucial.

Metformin has been reported to have a favorable effect on glycemic control in patients with T2D regardless of obesity in both an observational study [5] and a clinical trial [6] in Japan. This oral antidiabetic agent, first marketed in Japan in 1961, is in the biguanide drug class and controls blood glucose mainly by suppressing gluconeogenesis in the liver [7]. Metformin is recommended as a first-line antidiabetic drug in patients with T2D in Western countries based on evidence that it decreases the risk of cardiovascular complications [8] and provides a number of other benefits, including a high efficacy for lowering glucose, low cost, and minimal hypoglycemia risk [9].

A decrease in the glycemic control effect has been reported in a meta-analysis of various types of dipeptidyl peptidase-4 inhibitors (DPP4is) [10] and in an observational study on 
sitagliptin (a type of DPP-4i) [11] involving patients with T2D having high baseline BMI values ( $\geq 25$ or $\geq 30$ ). The results of a Japanese observational study suggested that a higher BMI is associated with a deterioration of glycemic control based on multiple linear regression analysis [12]. Another Japanese observational study indicated that sitagliptin is effective in obese patients with T2D; however, the effect may be attenuated in patients with $\mathrm{BMI} \geq 30$ [13]. Introduced into Japan in 2009, DPP-4is contribute to glycemic control by increasing the concentration of active forms of incretin hormones, such as glucagon-like peptide- 1 and glucose-dependent insulinotropic polypeptide, which are secreted after a meal to increase insulin secretion by the selective inhibition of DPP-4is [14]. DPP-4is are the most commonly used first-line antidiabetic agents in Japan because of multiple factors, including ease of use in patients with complications such as renal impairment [15]. Considering the increasing BMI values in patients with T2D in Japan and the differences in the effect of different treatments for glycemic control in patients with obesity, information to select the appropriate treatment in such patients is required to achieve the treatment goals. However, to date there is insufficient information available to compare the effect of metformin and DPP-4is, which are the first and second most common first-line antidiabetic drugs, respectively, in Japanese patients with T2D with high BMI values.

In this study we compared the effects of metformin and DPP-4is as first-line treatment on glycemic control in patients with T2D stratified by their BMI values who were included in a Japanese database that includes claims data and annual medical checkup data. The study also compared the effect of metformin and DPP4 is on improvement of other health outcomes, such as laboratory test values and BMI. The aim of this study was to provide information that will aid clinicians in selecting the appropriate first-line treatment drug; thus, the study period included the period after initial treatment, regardless of whether the first-line treatment was prescribed as monotherapy or not. Notably, the World Health Organization (WHO) defines the international cutoff point for overweight as
BMI $\geq 25$ and for obesity as $\geq 30$ [16-18]. Furthermore, WHO suggests applying lower cutoff points for Asian individuals due to their higher body fat percentage and obesity-related risks compared to populations in European countries at the same BMI $[17,18]$. Therefore, we defined the cutoff value for obesity at BMI $\geq 25$ according to the definition of obesity by the Japan Society for the Study of Obesity [19].

\section{METHODS}

\section{Study Design and Data Source}

This retrospective cohort study used a Japanese health insurance claims database (January 2005-August 2018) provided by JMDC, Inc. The database consisted of data from 5,840,945 individuals who were employees (and their family members) of companies that subscribe to the health insurance societies; few individuals in the database were aged $\geq 65$ years and even fewer were aged $\geq 75$ years. The database comprised comprehensive records of all diagnoses and treatments during the period when the member was covered with one insurance society. Although the database did not contain laboratory data, it did contain annual medical checkup data for some individuals.

This study has been reported according to the REporting of studies Conducted using Observational Routinely-collected health Data (RECORD) Statement [20]. The study was approved by the Institutional Review Board of Tokyo Medical University (T2019-0122). Since the study only used anonymized pre-existing data in the database, informed consent was not required [21]. The data that support the findings of this study are available from JMDC Inc. Restrictions apply to the availability of these data, which were used under license for this study. Data are available from the authors with the permission of JMDC Inc.

\section{Patient Identification}

Patients identified for the analyses were those who met all of the inclusion criteria and did not 
meet any exclusion criteria. The inclusion criteria were:

(1) A first diagnosis of T2D coded as E10 or E14 based on the International Statistical Classification of Diseases and Related Health Problems, 10th revision (ICD-10) [22] between May 2010 and June 2017. First diagnosis was defined as the earliest diagnosis during the observation period with $\geq 6$ months of a retrospective review period before the diagnosis. The observation period was defined as the insurance period for each individual.

(2) Age $\geq 18$ years at first diagnosis of T2D.

(3) Metformin or a DPP-4i [defined by the generic name; see Electronic Supplementary Material (ESM) Table S1 for details] prescribed as the index drug, and no prescription for any other antidiabetic drugs during the index month. The type of drug prescribed as the first antidiabetic drug (metformin or DPP-4i) after the diagnosis of T2D was defined as the index drug. The antidiabetic drug was coded as A10, according to the Anatomical Classification of Pharmaceutical Products (ATC) code. The index month was defined as the first month the index drug was prescribed.

(4) Data on laboratory values of glycated hemoglobin (HbA1c), both during the baseline period (a 3-month period including the index month and 2 months before the index month) and evaluation point (at the month of evaluation, which was 12 months ( \pm 3 months) from the index month).

(5) Data on BMI values during the baseline period.

The exclusion criteria were:

(1) Diagnosis of type 1 diabetes at least once, coded as E10, during the observation period.

(2) Administration of steroids for internal use during the baseline period or evaluation period, which refers to the duration from the index month to the evaluation point, because steroids can influence the glucoselowering effect of the drugs prescribed.
(3) Prescription for metformin by a Department of Obstetrics or Breast Surgery, possibly for reasons other than diabetes treatment.

(4) Prescription for metformin or DPP-4is outside the normal dose range during the evaluation period (see ESM Table S1 for details)

The identified patients were divided into two groups based on the type of index drug, i.e., metformin and DPP-4i groups. All identified patients were analyzed as those in each group, regardless of whether they maintained the same treatment pattern for the initial treatment or not.

\section{Outcomes}

Annual medical checkup data were used to evaluate the outcomes. The primary outcome was the mean reduction rate of excessive HbA1c $(>6.5 \%)$ at the evaluation point, which was plotted according to integer values of baseline BMI. It has been reported that the magnitude of change in HbA1c level is associated with baseline HbA1c levels, i.e., higher baseline values are associated with a greater reduction in HbA1c [23]. Therefore, the primary outcome was defined as the glycemic control effect, i.e., reduction in excessive HbA1c. To eliminate the effect of baseline HbA1c levels, the reduction was calculated from a value of $6.5 \%$, which is considered to be the cutoff point for the diagnosis of diabetes $[4,24]$. The reduction rate of excessive HbA1c was calculated as follows:

$$
\begin{aligned}
& \text { Reduction rate of excessive } \operatorname{HbA} 1 \mathrm{c}(\%) \\
& \quad=1-\left(\mathrm{HbA}_{1} \mathrm{c}_{12}-6.5\right) /\left(\mathrm{HbA}_{1} \mathrm{c}_{0}-6.5\right)
\end{aligned}
$$

where $\mathrm{HbA}_{1} \mathrm{c}_{0}$ and $\mathrm{HbA1} \mathrm{c}_{12}$ represent $\mathrm{HbA1c}$ at baseline and at the evaluation point, respectively.

Secondary outcomes were the changes from baseline to the evaluation point in the following laboratory values or in anthropometric data: HbA1c, fasting plasma glucose (FPG), BMI, triglyceride, high-density lipoprotein cholesterol (HDL-C), low-density lipoprotein cholesterol (LDL-C), and abdominal circumference, as 
well as the percentage of patients who achieved target HbA1c $(<7.0 \%)$ and percentage of patients who took additional therapy at the evaluation point. The additional therapy was defined as added treatment with antidiabetic drug or drugs other than the index drug during the evaluation period, regardless of whether the index drug was prescribed or not. As additional secondary outcomes, the values for primary and secondary outcomes were also compared between treatment groups by dividing the patients into those with BMI $<25$ and $\geq 25$, respectively, after confirming the continuity and tendency of mean values of outcomes by baseline BMI values.

\section{Analysis}

The mean values were plotted by integer values of the baseline BMI by treatment group for each outcome after adjusting confounding factors of the treatment groups using propensity score (PS) to confirm the continuity and tendency of the mean values. We also examined the correlation between the mean reduction rate of excessive HbA1c at the evaluation point and the baseline BMI values for which the number of patients was $\geq 30$ in both treatment groups, by the least squares method for each treatment group or the difference between treatment groups.

Next, each outcome was compared between treatment groups by dividing the patients into those with BMI $<25$ and those with BMI $\geq 25$. Confounding factors were adjusted by PS in each patient group of $\mathrm{BMI}<25$ and $\geq 25$. The difference between treatment groups was assessed by the $t$ test. Throughout the study, $p<0.05$ by the $t$ test was statistically significant.

The PS was separately developed for those patients with $\mathrm{BMI}<25$ and those with BMI $\geq 25$. The score was estimated using a logistic regression model with metformin prescription as the explained variable, and the following items at baseline as the explanatory variables: age; sex; annual checkup data (systolic blood pressure, triglycerides, LDL-C, aspartate aminotransferase, alanine aminotransferase, hemoglobin, abdominal circumference, and urinary protein); answers to annual checkup questionnaires on lifestyle (excluding items for which $<$ $70 \%$ patients had records; see ESM Table S2 for details); existence of diagnosis with endocrine diseases; existence of diagnosis with malignant neoplasms; and Charlson Comorbidity Index $[25,26]$. Missing data for the explanatory variables were imputed by the multiple imputation method using the SAS PROC MI procedure (SAS Institute, Cary, NC, USA). For the adjustment, the weight of each patient was calculated by dividing the total number of patients in both treatment groups in the quintile by the number of patients in the treatment group in the quintile (see ESM Table S3 for details) [27].

To explore the reasons for the higher percentage of additional therapy in the metformin group than that in the DPP-4i group, the status of change in treatment (combination, switch, or discontinuation) by dosage of metformin at first prescription was analyzed in the metformin group. In this analysis, if metformin was prescribed for 2 consecutive months from the same month as the first prescription of another antidiabetic drug(s) (defined as A10 by ATC code), change in treatment was defined as a combination therapy; if not, change in treatment was defined as a switch therapy. If patients did not receive any antidiabetic drugs for $\geq 3$ consecutive months, the change in treatment was defined as discontinuation.

For analyses in this study, The SAS statistical software package version 9.4 (SAS Institute) and Microsoft Excel 2016 (Microsoft Corp., Redmond, WA, USA) were used.

\section{RESULTS}

\section{Patients}

Among the 166,278 patients diagnosed with T2D between May 2010 and June 2017 in the database, 2548 patients, including 189 patients with BMI $<25$ and 588 patients with BMI $\geq 25$ taking metformin and 697 with $\mathrm{BMI}<25$ and 1074 with BMI $\geq 25$ taking DPP-4i, were identified (Tables 1, 2).

The patient attributes and laboratory test data at baseline in each treatment group 
stratified by BMI are shown in Table 2. Mean [standard deviation (SD)] age at index was 53.1 (7.4) and 54.3 (7.4) years in the metformin and DPP-4i groups, respectively, with BMI $<25$, and

Table 1 Patient identification criteria

\begin{tabular}{|c|c|}
\hline Criteria & $\begin{array}{l}\text { No. of } \\
\text { patients }\end{array}$ \\
\hline All individuals in the database & $5,840,945$ \\
\hline $\begin{array}{l}\text { First diagnosis of T2D coded as E10 or E14 } \\
\text { based on the ICD-10 between May } 2010 \\
\text { and June } 2017\end{array}$ & 166,278 \\
\hline Age $\geq 18$ years at the first diagnosis of T2D & 163,054 \\
\hline $\begin{array}{l}\text { Prescribed either metformin or DPP- } 4 \mathrm{i} \text { as } \\
\text { index drug, and no prescription of } \\
\text { antidiabetic drugs coded as A10 by ATC } \\
\text { code other than the index drug during the } \\
\text { month of the initial treatment }\end{array}$ & 19,352 \\
\hline $\begin{array}{l}\text { Laboratory values of HbAlc available both } \\
\text { during baseline period and evaluation } \\
\text { point of outcomes: after } 12 \text { months ( } \pm \\
3 \text { months) from the index month }\end{array}$ & 3,303 \\
\hline $\begin{array}{l}\text { Laboratory values of BMI available during } \\
\text { baseline period }\end{array}$ & 3,303 \\
\hline $\begin{array}{l}\text { No diagnosis of T1D coded as E10 during } \\
\text { the observation period }\end{array}$ & 3,273 \\
\hline $\begin{array}{l}\text { No prescription of steroids for internal use } \\
\text { during the baseline period and evaluation } \\
\text { period }\end{array}$ & 2,972 \\
\hline $\begin{array}{l}\text { No prescription of metformin from a } \\
\text { Department of Obstetrics or for breast } \\
\text { surgery }\end{array}$ & 2,962 \\
\hline $\begin{array}{l}\text { No prescription of metformin or DPP- } 4 \mathrm{i} \\
\text { outside the normal dose during the } \\
\text { evaluation period }\end{array}$ & 2,548 \\
\hline
\end{tabular}

$A T C$ Anatomical classification of pharmaceutical products, $B M I$ body mass index, DPP- $4 i$ dipeptidyl peptidase- 4 inhibitors, $H b A 1 c$ glycated hemoglobin, ICD-10 International Statistical Classification of Diseases and Related Health Problems, 10th revision, TID type 1 diabetes, T2D type 2 diabetes
48.1 (7.6) and 50.2 (7.7) years, respectively, with BMI $\geq 25$ (Table 2). The mean (SD) HbA1c level tended to be higher in the DPP-4i group than in the metformin group in patients with BMI $<25$ [8.02\% (1.80\%) vs. 7.87\% (1.60\%), respectively], whereas it tended to be higher in the metformin group in patients with $\mathrm{BMI} \geq 25[8.13 \%(1.65 \%)$ vs. $7.96 \%(1.53 \%)]$. In comparison with the baseline BMI values of these patients, in both treatment groups those with baseline BMI $\geq 25$ had higher mean values for all analyzed laboratory and anthropometric data except for HbA1c than those with BMI $<25$.

Among the checkup questionnaires on lifestyles, eating habits (snack between meals, data available for $24 \%$ patients) and mastication function (data available for $0 \%$ patients) were excluded for PS development due to insufficient data (see ESM Table S2 for details). The number of patients in each quintile of PS are shown in ESM Table S3.

\section{Comparison of Outcomes by Each Integer Value of Baseline BMI}

The mean reduction rate of excessive HbA1c by integer values of baseline BMI by treatment group is shown in Fig. 1a. The value was distributed successively, without any marked transition points. It was higher in the metformin group than in the DPP-4i group for the most of baseline BMI values; in particular for the points denoting $\mathrm{BMI} \geq 25$. No correlation, as suggested by a low $R^{2}$ value, was found between the mean reduction rate and baseline BMI values for both treatment groups (Fig. 1b) and the difference between the treatment groups that was calculated as (value of metformin group) - (value of DPP-4i group) (Fig. 1c).

Successive distribution of the mean values was also observed for secondary outcomes (see ESM Fig. S1 for details). A tendency for greater improvement from baseline was observed in some values, including the HbA1c, FPG, and $\mathrm{BMI}$ at the evaluation point in the metformin group compared with those in the DPP-4i group for many integer values of baseline BMI $\geq 25$. 
Table 2 Baseline demographic and laboratory data for patients stratified by BMI

\begin{tabular}{|c|c|c|c|c|}
\hline \multirow[t]{2}{*}{ Patient data } & \multicolumn{2}{|l|}{ BMI $<25$} & \multicolumn{2}{|l|}{ BMI $\geq 25$} \\
\hline & MET & DPP-4i & MET & DPP-4i \\
\hline Number of patients & 189 & 697 & 588 & 1,074 \\
\hline Male patients (\%) & 83.6 & 82.2 & 85.7 & 85.7 \\
\hline Age at index (years) & $53.1 \pm 7.4$ & $54.3 \pm 7.4$ & $48.1 \pm 7.6$ & $50.2 \pm 7.7$ \\
\hline HbAlc (\%) & $7.87 \pm 1.60$ & $8.02 \pm 1.80$ & $8.13 \pm 1.65$ & $7.96 \pm 1.53$ \\
\hline BMI $\left(\mathrm{kg} / \mathrm{m}^{2}\right)$ & $23.0 \pm 1.5$ & $22.6 \pm 1.7$ & $30.0 \pm 4.2$ & $29.2 \pm 3.7$ \\
\hline $\mathrm{SBP}(\mathrm{mmHg})$ & $125 \pm 16$ & $128 \pm 17$ & $131 \pm 17$ & $131 \pm 16$ \\
\hline Triglyceride (mg/dl) & $140 \pm 98$ & $145 \pm 120$ & $167 \pm 128$ & $166 \pm 121$ \\
\hline LDL-C (mg/dl) & $117 \pm 29$ & $120 \pm 31$ & $122 \pm 30$ & $123 \pm 31$ \\
\hline $\operatorname{AST}(\mathrm{U} / \mathrm{L})$ & $24.0 \pm 12.7$ & $24.6 \pm 12.6$ & $31.5 \pm 21.1$ & $30.1 \pm 18.0$ \\
\hline $\operatorname{ALT}(\mathrm{U} / \mathrm{L})$ & $27.9 \pm 17.6$ & $27.7 \pm 19.5$ & $43.8 \pm 32.3$ & $40.6 \pm 28.2$ \\
\hline Hemoglobin $(\mathrm{g} / \mathrm{dl})$ & $14.8 \pm 1.2$ & $14.8 \pm 1.3$ & $15.4 \pm 1.3$ & $15.4 \pm 1.3$ \\
\hline Abdominal circumference $(\mathrm{cm})$ & $82.9 \pm 5.8$ & $81.9 \pm 6.1$ & $97.3 \pm 10.8$ & $95.7 \pm 9.5$ \\
\hline
\end{tabular}

Values in table are presented as the mean \pm standard deviation $A L T$ Alanine aminotransferase, $A S T$ aspartate aminotransferase, $L D L-C$ low-density lipoprotein cholesterol, $M E T$ metformin, $S B P$ systolic blood pressure

\section{Comparison of Outcomes Stratified by $\mathrm{BMI} \geq 25$ at Baseline}

Because there was no specific transition point of baseline BMI values for each outcome (Fig. 1; ESM Fig. S1), the patients were divided into non-obesity and obesity groups, with the threshold being BMI 25 at baseline, in accordance to the definition of obesity by the Japan Society for the Study of Obesity [19]. In patients with $\mathrm{BMI} \geq 25$, the reduction rate of excessive HbA1c was significantly higher in the metformin group than in the DPP-4i group (70.8 vs. $49.8 \%$, respectively; $p=0.013$; Table 3 ). Most test values, excluding those for triglycerides and LDL-C, showed a statistically significant greater improvement in the metformin group than in the DPP-4i group. The percentage of patients who achieved target HbA1c level was also higher in the metformin group than in the DPP$4 \mathrm{i}$ group $(64.4$ vs. $59.6 \%$, respectively; $p=0.031)$. The outcomes with statistically significant difference between the treatment groups were fewer in patients with $\mathrm{BMI}<25$ than those with $\mathrm{BMI} \geq 25$. The reduction rate of excessive HbA1c, BMI, and abdominal circumference were more improved in the metformin group than in the DPP-4i group. In contrast, improvement in HbA1c was significantly greater in the DPP-4i group (1.20\% reduction) than in the metformin group $(0.90 \%$ reduction; $p=0.006)$. The percentage of patients with an additional therapy was significantly higher in both metformin groups (i.e., patients with BMI $<25$ and $\geq 25 ; 28.3$ and $30.6 \%$, respectively) compared with the DPP-4i groups (20.4 and $21.5 \%$, respectively; $p=0.012$ and $p<0.001$, respectively).

\section{Relationship of Additional Therapy and Metformin Dose}

To explore the use of additional therapy for patients in the metformin group, we 


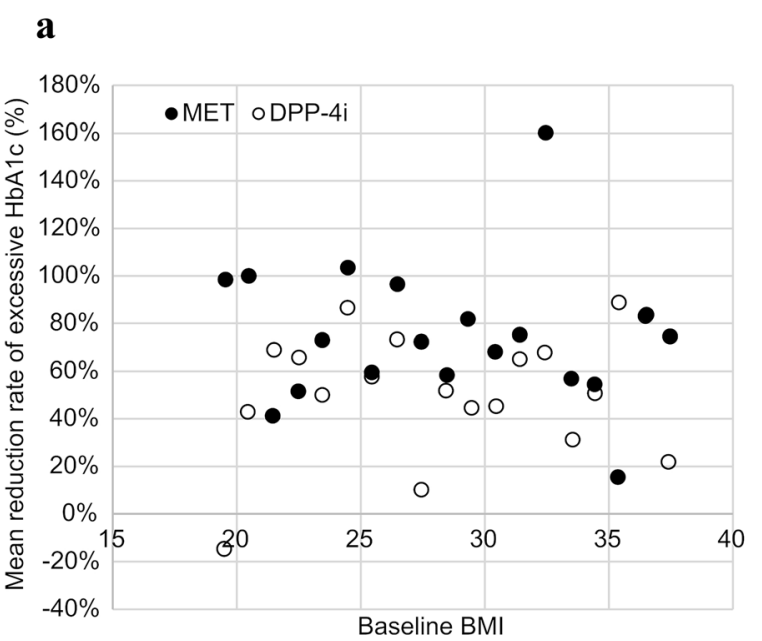

\section{b}

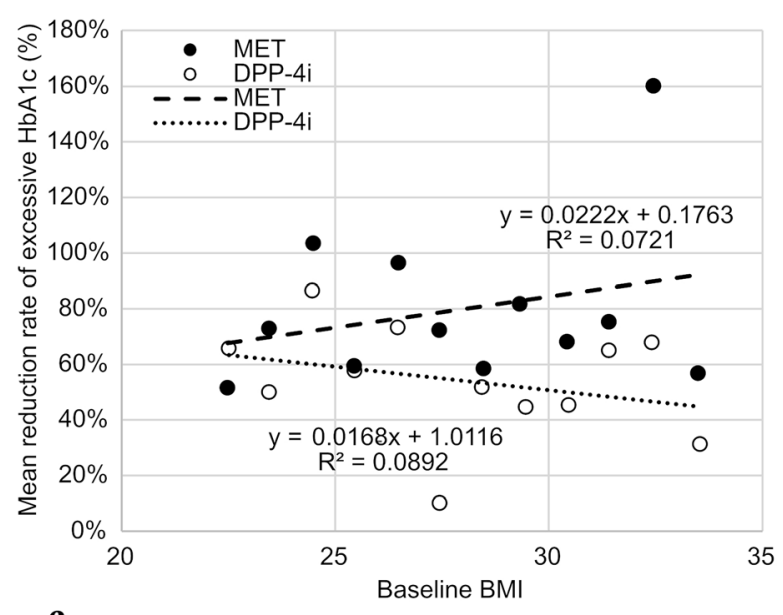

c

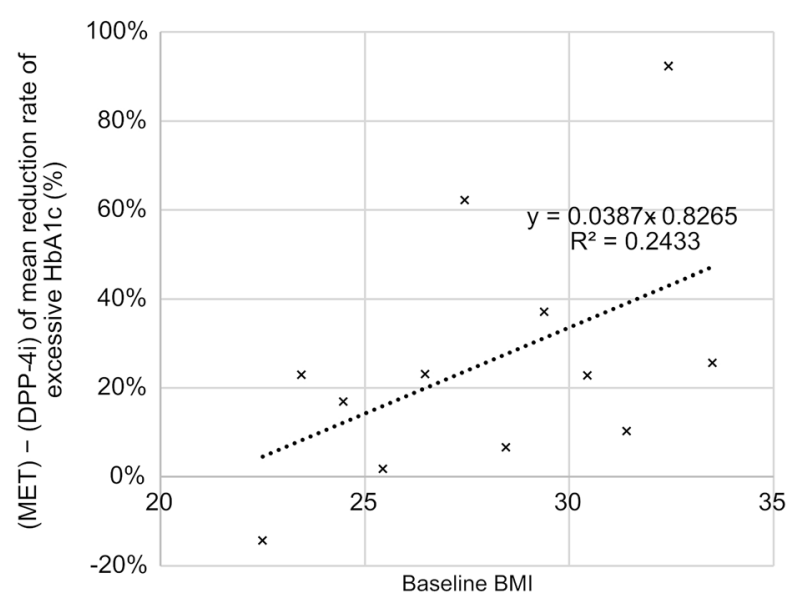

4Fig. 1 Mean reduction rate of excessive HbAlc plotted according to baseline integer BMI values by treatment group in all patients (a) and in patients with BMI 22-33 (b) with trend line, equation, and $R^{2}$ value. c Difference between treatment groups (metformin - DPP-4i) at BMI 22-33 with trend line, equation, and $R^{2}$ value. BMI Body mass index, $D P P-4 i$ dipeptidyl peptidase-4 inhibitor, $H b A 1 c$ glycated hemoglobin A, MET metformin

investigated the status of additional therapy by the initial dose of metformin. The most frequent dose both at first prescription and after 1 year from the index month was $500 \mathrm{mg}$ /day in all patients and in those with $\mathrm{BMI}<25$ and $\geq 25$ (see ESM Table S4 for details). Mean metformin dose at first prescription was 638, 635, and $639 \mathrm{mg} /$ day in all patients, those with $\mathrm{BMI}<25$, and those with $\mathrm{BMI} \geq 25$, respectively; and the dose after 1 year from the index month, excluding those with no prescription of metformin at the time, was 805, 736, and $827 \mathrm{mg} /$ day, respectively.

There were 659 and 118 patients in the metformin group who received $\leq 750$ and $\geq$ $1000 \mathrm{mg} /$ day as initial treatment, respectively (see ESM Table S4 for details). The percentage of patients who took combination therapy was significantly higher in those receiving $\leq 750 \mathrm{mg} /$ day of metformin (15.3\%) than in those taking $\geq 1000 \mathrm{mg} /$ day metformin (9.3\%; $p=0.023)$. The percentage of patients with switch therapy and discontinuation was higher in patients taking $\geq 1000 \mathrm{mg} /$ day $(18.6$ and $33.9 \%$, respectively) than in those taking $\leq$ $750 \mathrm{mg} /$ day (16.1 and $28.2 \%$, respectively), but the differences were not statistically significant ( $p=0.254$ and $p=0.114$, respectively).

\section{DISCUSSION}

The aim of this study was to compare metformin and DPP-4is as first-line treatment in Japanese patients with T2D to investigate the effects of these antidiabetics on glycemic control and the improvement of health outcomes in obese and non-obese patients using a claims database that included annual medical checkup 
Table 3 Comparison of outcomes between treatment groups stratified by BMI

\begin{tabular}{|c|c|c|c|c|c|c|c|c|}
\hline \multirow{2}{*}{$\begin{array}{l}\text { Treatment } \\
\text { outcomes }^{a}\end{array}$} & \multicolumn{4}{|l|}{ BMI $<25$} & \multicolumn{4}{|l|}{$\mathrm{BMI} \geq 25$} \\
\hline & $\overline{M E T}(\mathrm{M})$ & DPP-4i (D) & $\mathbf{M}-\mathbf{D}$ & $p$ value & MET (M) & DPP-4i (D) & $\mathbf{M}-\mathbf{D}$ & $p$ value \\
\hline $\begin{array}{l}\text { Reduction rate of } \\
\text { excessive HbAlc } \\
(\%)\end{array}$ & $79.2(8.40)$ & $60.0(7.70)$ & $19.1^{*}$ & 0.046 & $70.8(7.16)$ & $49.8(6.16)$ & $21.0^{*}$ & 0.013 \\
\hline$\Delta \mathrm{HbAlc}(\%)$ & $\begin{array}{r}-0.90 \\
(0.10)\end{array}$ & $\begin{array}{r}-1.20 \\
(0.06)\end{array}$ & $0.30^{*}$ & 0.006 & $\begin{array}{c}-1.14 \\
0.06)\end{array}$ & $\begin{array}{r}-0.92 \\
(0.05)\end{array}$ & $-0.22^{*}$ & 0.003 \\
\hline $\begin{array}{l}\text { \% Target HbAlc } \\
(<7 \%) \\
\text { achievement }\end{array}$ & $68.1(3.43)$ & $68.8(1.75)$ & -0.7 & 0.428 & $64.4(2.05)$ & $59.6(1.48)$ & $4.7^{*}$ & 0.031 \\
\hline$\Delta \mathrm{FPG}(\mathrm{mg} / \mathrm{dl})$ & $\begin{array}{r}-22.4 \\
(3.32)\end{array}$ & $\begin{array}{r}-27.7 \\
(2.05)\end{array}$ & 5.3 & 0.085 & $\begin{array}{r}-28.4 \\
(2.08)\end{array}$ & $\begin{array}{r}-21.7 \\
(1.64)\end{array}$ & $-6.8^{*}$ & 0.005 \\
\hline$\Delta \mathrm{BMI}\left(\mathrm{kg} / \mathrm{m}^{2}\right)$ & $\begin{array}{r}-0.34 \\
(0.08)\end{array}$ & $\begin{array}{r}-0.13 \\
(0.04)\end{array}$ & $-0.21^{*}$ & 0.008 & $\begin{array}{r}-0.64 \\
(0.06)\end{array}$ & $\begin{array}{r}-0.46 \\
(0.05)\end{array}$ & $-0.18^{*}$ & 0.006 \\
\hline $\begin{array}{c}\Delta \text { Triglyceride } \\
(\mathrm{mg} / \mathrm{dl})\end{array}$ & $\begin{array}{r}-31.1 \\
(9.79)\end{array}$ & $\begin{array}{r}-37.8 \\
(6.09)\end{array}$ & 6.7 & 0.282 & $\begin{array}{r}-45.5 \\
(6.83)\end{array}$ & $\begin{array}{r}-36.8 \\
(4.43)\end{array}$ & -8.7 & 0.142 \\
\hline$\Delta \mathrm{HDL}-\mathrm{C}(\mathrm{mg} / \mathrm{dl})$ & $1.69(0.55)$ & $1.520 .30)$ & 0.17 & 0.393 & $1.98(0.26)$ & $1.37(0.22)$ & $0.61^{*}$ & 0.035 \\
\hline$\Delta \mathrm{LDL}-\mathrm{C}(\mathrm{mg} / \mathrm{dl})$ & $\begin{array}{r}-11.5 \\
(2.28)\end{array}$ & $\begin{array}{r}-13.7 \\
(1.33)\end{array}$ & 2.2 & 0.205 & $\begin{array}{r}-15.1 \\
(1.43)\end{array}$ & $\begin{array}{r}-12.6 \\
(0.96)\end{array}$ & -2.6 & 0.068 \\
\hline $\begin{array}{l}\Delta \text { Abdominal } \\
\text { circumference } \\
(\mathrm{cm})\end{array}$ & $\begin{array}{r}-0.91 \\
(0.22)\end{array}$ & $\begin{array}{r}-0.48 \\
(0.13)\end{array}$ & $-0.43^{*}$ & 0.049 & $\begin{array}{r}-1.54 \\
(0.18)\end{array}$ & $\begin{array}{r}-1.11 \\
(0.13)\end{array}$ & $-0.43^{*}$ & 0.027 \\
\hline$\%$ Additional therapy & $28.3(3.10)$ & $20.4(1.57)$ & $7.9^{*}$ & 0.012 & $30.6(1.82)$ & $21.5(1.28)$ & $9.2^{*}$ & 0.000 \\
\hline
\end{tabular}

data. The mean reduction rate of excessive HbA1c plotted based on baseline integer BMI values distributed successively and without any marked transition points in both treatment groups. The values tended to be higher in the metformin group than in the DPP-4i group, particularly in patients with $\mathrm{BMI} \geq 25$.

In the patient groups with $\mathrm{BMI} \geq 25$, a higher reduction rate of excessive HbA1c, greater reduction in HbA1c level, and higher percentage of patients who achieved target HbA1c were observed in the metformin group compared with the DPP-4i group. In contrast, in the patient groups with $\mathrm{BMI}<25$, although the reduction rate of excessive $\mathrm{HbA1c}$ was higher in the metformin group, the reduction in HbA1c level was greater in the DPP-4i group, and no significant difference was observed in the percentage of achieved target HbA1c between treatment groups. Metformin has been reported to show a glycemic control effect regardless of BMI values $[5,6]$, whereas a decrease in the effect associated with higher baseline BMI values has been reported for DPP-4is [10, 11]. Considering these previous reports, in patients with $\mathrm{BMI}<25$, a glycemic control effect was 
shown with both treatments; meanwhile, for patients with $\mathrm{BMI} \geq 25$, a similar effect was shown by the treatment with metformin, and the effect decreased in the group treated with DPP-4is, resulting in a more significant hypoglycemic effect in the metformin group compared with the DPP-4i group.

In this study, the decrease in HbA1c level ( 0.90 and $1.14 \%$ for patients with $\mathrm{BMI}<25$ and $\mathrm{BMI} \geq 25$, respectively) was smaller than that in a previous study, with a mean age 58.0 years, $62.2 \%$ male, mean baseline HbA1c level of $7.72 \%$, and $49.4 \%$ of participants with $\mathrm{BMI} \geq 25$ [6]. In that study, relative to baseline the HbA1c level decreased by $1.33 \%$ in patients with BMI $<22$, by $1.18 \%$ in those with $\mathrm{BMI} \geq 22$ and $<25$, and by $1.38 \%$ for $\mathrm{BMI} \geq 25$ at the final evaluation ( $>54$ weeks) among patients treated with metformin monotherapy. This discrepancy from our results is probably due to the differences in patient characteristics and evaluation time from baseline. In addition, the dose of metformin may be associated with this difference between studies. In the previous study [6], of the 80 patients receiving metformin, 62 received $1500 \mathrm{mg} /$ day and 15 received $2250 \mathrm{mg} /$ day as the most common dose. In the current study, most patients started metformin at $500 \mathrm{mg} / \mathrm{day}$, and most patients were still taking $<1000 \mathrm{mg} /$ day at the evaluation point.

In terms of the metformin dose, the effect on reduction in HbA1c level was reported to be similar between monotherapy with metformin at $1000 \mathrm{mg} /$ day and with vildagliptin at $100 \mathrm{mg} /$ day $[28,29]$. Considering the metformin dose in this study, a lower reduction in HbA1c level in patients in the metformin group than in those in the DPP-4i group in patients with $\mathrm{BMI}<25$ is reasonable. We observed that patients in the metformin group with BMI $\geq 25$ showed a greater effect of reduction in HbA1c level as well as improvement in other outcomes, including BMI, abdominal circumference, triglyceride, and HDL-C, than their BMI counterparts in the DPP-4i group, even though the metformin dose was low in these patients. Consequently, preferable effect by treatment with metformin was confirmed in obese patients.
This study had several limitations. Because the study participants were members of a health insurance society and had a record of annual medical checkups, most were aged $<65$ years and there was a high percentage of men (>80\%). Consequently, the generalizability of the results may be limited. Also, the PS was calculated using various items, including test values and annual checkup questionnaires on lifestyle, to adjust for the confounding factors. Because T2D is a lifestyle-related disease the inclusion of information on lifestyle may be one of the strengths of this study. However, because the study could include information only from the database, not all important confounders may have been included. In addition, because this study was based on the secondary use of claims data, the accuracy of diagnoses, treatments, and annual checkup data relies on the accuracy of the database records. Moreover, the reliability of answers to annual checkup questionnaires on lifestyle depends on the extent with which the patient answered veraciously. Although these limitations should be taken into account, to the authors' best knowledge, this study is the first to compare the effect on glycemic control between metformin and DPP-4i as a first-line antidiabetic treatment in patients with T2D by BMI values. Thus, this study may be expected to contribute to decision-making when choosing a first-line antidiabetic treatment in this patient population.

\section{CONCLUSION}

The results of this study suggest that the effect of glycemic control and improvement in other health outcomes, including obesity, is higher with metformin treatment as a first-line drug than with DPP-4is in Japanese obese patients with T2D. We believe that this finding provides information that will help clinicians choose an appropriate treatment when considering the conditions for each patient, including BMI value. Further studies on metformin dosage and concomitant antidiabetic drugs may be expected to reveal the effect of metformin in obese patients with T2D. 


\section{ACKNOWLEDGEMENTS}

The authors would like to thank Kenji Baba (Sumitomo Dainippon Pharma Co., Ltd.) for his contribution to the study design.

Funding. Sponsorship for this study and the Journal's Rapid Service Fee were funded by Sumitomo Dainippon Pharma Co., Ltd.

Authorship. All named authors meet the International Committee of Medical Journal Editors (ICMJE) criteria for authorship for this article, take responsibility for the integrity of the work as a whole, and have given their approval for this version to be published.

Author Contributions. MO and SA contributed to the study conception. All authors were involved in the study design and interpretation of data. KI performed the data analysis. TT drafted the manuscript, and all authors contributed to the critical review of the previous versions of the manuscript. All authors approved the final manuscript.

Medical Writing, Editorial, and Other Assistance. Editorial assistance in the preparation of this article was provided by Enago (www.enago.jp). Support for this assistance was funded by Sumitomo Dainippon Pharma Co., Ltd.

Disclosures. Masato Odawara has received honoraria as lecturer from Sumitomo Dainippon Pharma Co., Ltd., Taisho Pharmaceutical Co., Ltd., Novartis Pharma K.K., Eli Lilly Japan. K.K., Astellas Pharma Inc., Ono Pharmaceutical Co., Ltd., Kyowa Kirin Co., Ltd., Daiichi Sankyo Co., Ltd., Takeda Pharmaceutical Co. Ltd., Mitsubishi Tanabe Pharma Corp., Nippon Boehringer Ingelheim Co. Ltd., and MSD K.K.; research funding from AstraZeneca K.K., Sanofi K.K., Sumitomo Dainippon Pharma Co., Ltd., Eli Lilly Japan K.K., and Novo Nordisk Pharma Ltd.; and scholarship grants from MSD K.K., Astellas Pharma Inc., AstraZeneca K.K., Ono Pharmaceutical Co., Ltd., Kyowa Kirin Co., Ltd., Kowa Co., Ltd., Sanofi K.K., Daiichi Sankyo Co., Ltd., Taisho Pharmaceutical Co., Ltd.,
Sumitomo Dainippon Pharma Co., Ltd., Takeda Pharmaceutical Co. Ltd., Mitsubishi Tanabe Pharma Corp., Teijin Healthcare Ltd., Eli Lilly Japan K.K., Nippon Boehringer Ingelheim Co. Ltd., Novartis Pharma K.K., and Novo Nordisk Pharma Ltd. Sumiko Aoi is an employee of Sumitomo Dainippon Pharma Co., Ltd. Tomomi Takeshima and Kosuke Iwasaki are employees of Milliman Inc., which has received consultancy fees from Sumitomo Dainippon Pharma Co., Ltd. Masato Odawara is currently affiliated with the Department of Diabetes, Metabolism and Endocrinology, Sanno Hospital (Tokyo, Japan) and the Department of Medicine, International University of Health and Welfare (Tokyo Japan), in addition to Tokyo Medical University.

Compliance with Ethics Guidelines. The study was approved by the Institutional Review Board of Tokyo Medical University (T20190122). Since the study only used anonymized pre-existing data in the database, informed consent was not required.

Data Availability. The data that support the findings of this study are available from JMDC Inc. Restrictions apply to the availability of these data, which were used under license for this study. Data are available from the authors with the permission of JMDC Inc.

Open Access. This article is licensed under a Creative Commons Attribution-NonCommercial 4.0 International License, which permits any non-commercial use, sharing, adaptation, distribution and reproduction in any medium or format, as long as you give appropriate credit to the original author(s) and the source, provide a link to the Creative Commons licence, and indicate if changes were made. The images or other third party material in this article are included in the article's Creative Commons licence, unless indicated otherwise in a credit line to the material. If material is not included in the article's Creative Commons licence and your intended use is not permitted by statutory regulation or exceeds the permitted use, you will need to obtain permission directly from the copyright holder. To view a copy of this licence, 
visit http://creativecommons.org/licenses/bync/4.0/.

\section{REFERENCES}

1. Ministry of Health, Labour and Welfare. National Health and Nutrition Survey in Japan, 2016. 2017. https://www.mhlw.go.jp/content/000681180.pdf. Accessed 5 Jan 2021. (In Japanese).

2. Japan Diabetes Clinical Data Management Study Group. Basic Data Document 2017. 2017. http:// jddm.jp/data/index-2017/. Accessed 5 Jan 2021. (In Japanese).

3. Gerstein HC, Miller ME, Byington RP, et al. Effects of intensive glucose lowering in type 2 diabetes. N Engl J Med. 2008;358:2545-59.

4. Araki E, Goto A, Kondo T, et al. Japanese clinical practice guideline for diabetes 2019. J Diabetes Investig. 2020;11:1020-76.

5. Kaku K, Tajima N, Kawamori R. Melbin observational research (MORE) study of metformin therapy in patients with type 2 diabetes mellitus. J Jpn Diabetes Soc. 2006;49:325-31. (In Japanese).

6. Odawara M, Kawamori R, Tajima N, et al. Longterm treatment study of global standard dose metformin in Japanese patients with type 2 diabetes mellitus. Diabetol Int. 2017;8:286-95.

7. Cusi K, Consoli A, DeFronzo RA. Metabolic effects of metformin on glucose and lactate metabolism in noninsulin-dependent diabetes mellitus. J Clin Endocrinol Metab. 1996;81:4059-67.

8. [No authors listed]. Effect of intensive blood-glucose control with metformin on complications in overweight patients with type 2 diabetes (UKPDS 34). UK Prospective Diabetes Study (UKPDS) Group. Lancet. 1998;352:854-65.

9. Davies MJ, D’Alessio DA, Fradkin J, et al. Management of hyperglycemia in type 2 diabetes, 2018. A consensus report by the American Diabetes Association (ADA) and the European Association for the Study of Diabetes (EASD). Diabetes Care. 2018;2018(41):2669-701.

10. Kim YG, Hahn S, Oh TJ, Kwak SH, Park KS, Cho YM. Differences in the glucose-lowering efficacy of dipeptidyl peptidase-4 inhibitors between Asians and non-Asians: a systematic review and metaanalysis. Diabetologia. 2013;56:696-708.
11. Kim SA, Shim WH, Lee EH, et al. Predictive clinical parameters for the therapeutic efficacy of sitagliptin in Korean type 2 diabetes mellitus. Diabetes Metab J. 2011;35:159-65.

12. Bando $\mathrm{Y}$, Kanehara $\mathrm{H}$, Aoki $\mathrm{K}$, Hisada A, Toya D, Tanaka N. Obesity may attenuate the HbA1c-lowering effect of sitagliptin in Japanese type 2 diabetic patients. J Diabetes Investig. 2012;3:170-4.

13. Kodera R, Shikata K, Nakamura A, et al. The glucose-lowering efficacy of sitagliptin in obese Japanese patients with type 2 diabetes. Intern Med. 2017;56:605-13.

14. Drucker DJ, Nauck MA. The incretin system: glucagon-like peptide-1 receptor agonists and dipeptidyl peptidase- 4 inhibitors in type 2 diabetes. Lancet. 2006;368:1696-705.

15. Murayama H, Imai K, Odawara M. Factors Influencing the prescribing preferences of physicians for drug-naive patients with type 2 diabetes mellitus in the real-world setting in Japan: insight from a web survey. Diabetes ther. 2018;9(3):1185-99.

16. World Health Organization. Fact sheets: obesity and overweight. 2021. https://www.who.int/newsroom/fact-sheets/detail/obesity-and-overweight. Accessed 24 May 2021.

17. World Health Organization. The Asia-Pacific perspective: redefining obesity and its treatment. Sydney: Health Communications Australia. 2000. https://apps.who.int/iris/bitstream/handle/10665/ 206936/0957708211_eng.pdf. Accessed 24 May 2021.

18. WHO Expert Consultation. Appropriate body-mass index for Asian populations and its implications for policy and intervention strategies. Lancet. 2004;363:157-63.

19. Japan Society for the Study of Obesity. Guideline for the management of obesity disease 2016. Tokyo: Life Science Publishing Co., Ltd.; 2016. (In Japanese).

20. Benchimol EI, Smeeth L, Guttmann A, et al. the reporting of studies conducted using observational routinely-collected health data (record) statement. PLoS Med. 2015;12:e1001885.

21. Ministry of Health, Labour and Welfare. Ethical guidelines for medical and health research involving human subjects. 2014 (revised in 2017). https:// www.mhlw.go.jp/file/06-Seisakujouhou-10600000Daijinkanboukouseikagakuka/0000153339.pdf. Accessed 05 Jan 2021. (In Japanese).

22. Ministry of Health, Labour and Welfare. Statistical classification of diseases and cause of death. 2013. 
http://www.mhlw.go.jp/toukei/sippei/. Accessed 05 Jan 2021. (In Japanese).

23. DeFronzo RA, Stonehouse AH, Han J, Wintle ME. Relationship of baseline HbA1c and efficacy of current glucose-lowering therapies: a meta-analysis of randomized clinical trials. Diabet Med. 2010;27: 309-17.

24. The International Expert Committee. International Expert Committee report on the role of the A1C assay in the diagnosis of diabetes. Diabetes Care. 2009;32:1327-34.

25. Charlson ME, Pompei P, Ales KL, MacKenzie CR. A new method of classifying prognostic comorbidity in longitudinal studies: development and validation. J Chronic Dis. 1987;40:373-83.

26. Quan H, Sundararajan V, Halfon P, et al. Coding algorithms for defining comorbidities in ICD-9-CM and ICD-10 administrative data. Med Care. 2005;43:1130-9.

27. Thourani VH, Kodali S, Makkar RR, et al. Transcatheter aortic valve replacement versus surgical valve replacement in intermediate-risk patients: a propensity score analysis. Lancet. 2016;387: 2218-25.

28. Odawara M, Hamada I, Suzuki M. Efficacy and Safety of vildagliptin as add-on to metformin in japanese patients with type 2 diabetes mellitus. Diabetes Ther. 2014;5:169-81.

29. Odawara M, Yoshiki M, Sano M, Hamada I, Lukashevich V, Kothny W. Efficacy and safety of a single-pill combination of vildagliptin and metformin in Japanese patients with type 2 diabetes mellitus: a randomized, double-blind, placebo-controlled trial. Diabetes Ther. 2015;6:17-27. 